\title{
Chinese Traditional Morality and Contemporary Moral Construction Chang $\mathrm{Liu}^{1, \mathrm{a},{ }^{\star}}$, Lin $\mathrm{Li}^{2, \mathrm{~b}}$,
}

${ }^{1}$ The zhuhai college of jilin university, jinwan, zhuhai, guangdong, China

${ }^{2}$ The zhuhai college of jilin university, jinwan, zhuhai, guangdong, China

a67203444@qq.com, b995633069@qq.com

${ }^{*}$ Chang Liu

Keywords: Chinese traditional culture, moral construction, connotation and path. \begin{abstract}
connotation.
\author{
中国传统师德观与当代师德建设

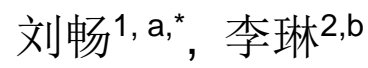 \\ 1吉林大学珠海学院中文系, 金湾, 珠海, 广东, 中国 \\ 2吉林大学珠海学院人事处, 金湾, 珠海, 广东, 中国 \\ a67203444@qq.com, b995633069@qq.com \\ *刘畅
}

Abstract. The construction of morality is very important to improve the overall quality of teachers. The excellent traditional culture of China includes rich philosophical thought, humanistic spirit, educational thought and moral idea. They can provide useful inspiration for people to understand and transform the world, which can provide useful enlightenment for the administration of state affairs and provide useful inspiration for moral construction. In the traditional culture, those suitable for strengthening and improving the moral construction of university teachers, we should combine them with the conditions of the times, to inherit and carry forward, and tap the historical

关键词: 中国传统文化; 高校师德建设; 内涵与路径

中文摘要. 师德建设关乎教师队伍的整体素质, 中国优秀传统文化的丰富哲学思想、人文精 神、教化思想、道德理念等可以为人们认识和改造世界提供有益启迪，可以为治国理政提供 有益启示, 也可以为道德建设提供有益启发。对传统文化中适合于加强和改进高校师德建设 的内容, 我们要结合时代条件加以继承和发扬, 挖掘其历史的内涵。

\section{1. 引言}

师德即教师的职业道德，是指教师从事教育劳动时所应遵循的行为规范和必备的思想品 德之总和。大学作为科学研究和培养人才的主阵地, 师德建设情况, 对社会各行业职业道德 建设更具有示范效应。本文旨在探讨高校开展师德建设需继承和发扬的传统精神财富, 丰富 高校师德建设的内涵与思路。 


\section{2. 中国传统 “师德” 观}

\section{1 重视师德, 选拔严格}

教学自身的示范性和教师的权威性决定了社会对教师有更高的严格要求, 故古人向来非 常重视师德。“务学不如务求师。师者, 人之模范也。” (杨雄《法言・学行》) 孟子也曾 指出, “弯之教人射, 必志于毅。大匠诲人必以规矩, 学者亦必以规矩。”（《孟子・告子 上》）教师因其思想道德的典范性决定了他们的言行必然是社会上下关注的焦点, 人们必然 对他们提出更高标准的道德要求。因而, “教, 上所施, 下所效也。” (《说文》) 在荀子 看来，教师直接关系国家兴亡的根本：“国将兴，必贵师而重傅”，“国将衰，必贱师而轻 傅”（《荀子・大略》) 汉代的董仲舒上书汉武帝建议: “兴太学，置明师，以养天下之士。” （董仲舒《对策二》）

古代不仅在道德上重视, 而且有 “严其选” 的制度保障。在明代, 地方官学满九年要重 新考核, 不合格者将被 “罚俸” 乃至 “罢黔”。《礼记・学记》：“择师不可不慎”、“三 王四代唯其师”，中国古代的历代帝王都十分重视选拔教师。孔子在《礼记・学记》中说 “古 之王者, 建国君民, 教学为先。” 朱喜也说: “国子先生, 必求天下贤士真可为师者。” (《学 校贡举合议》) 教师是大道的承载者, 君王要治理好国家, 必先从教育出发, 尊师重道, 教 化百姓。

\section{2 热爱学生, 甘于奉献}

中国古人的教育追求 “为天地立心，为生民立命，为往圣及绝学，为万世开太平”（北 宋张载），强调 “达则兼济天下，穷则独善其身”，普遍具有崇高的人生理想。而在人们心 目中, “师者, 传道受业解惑也”, 这就决定了教师有强烈的社会责任感和历史使命感。教 师是一个特殊的职业, 正式这个职业赋予他们献身理想的动力。所以, 他们一般都具有安贫 乐道、爱岗敬业、辛勤耕耘、无私奉献的高尚品格。

教师在教育学生培养人才的过程中获得辛福感和成就感。孟子曾感慨，“君子有三乐， 而王天下不与焉。父母俱在, 兄弟无故, 一乐也; 仰无愧于天, 俯不怍于人, 二乐也; 得天 下英才而教育之, 三乐也。”（《孟子・尽心上》）好教师必定爱护学生, 爱惜人才, 他把 “能得天下英才而教育之”视为人生一大乐事。

教师真正关爱学生就要不断鼓励学生。《论语・子罕》：“后生可畏，焉知来者之不如 今也?” 孔子鼓励学生 “当仁不让于师。” ( 《论语》) 韩愈也说: “弟子不必不如师, 师不 必贤于弟子。” (《师说》) 教师真正关爱学生就要做到 “有教无类” (《论语・卫灵公》)。

\section{3 为人师表, 以身作则}

我国古代的教育者非常讲究为人师表。教师是的全社会的表率，要做到严于律己，言传 身教, “其身正, 不令而行。其身不正, 虽令不从。”（《论语・子路》）孟子说: “大人者, 正己而物正者也。”（《孟子・尽心上》）教育者必先自正, 才能他正。清代王夫之也指出 “师弟子者以道相交而为人伦之一。……故欲正天下之人心，须顺天下之师受。主教为本， 躬行为起化之原。”（王夫之《四书训义》）意在说明教师的教育关系到整个社会的人伦道 德，而教师自身言行的表率作用则是使学生思想品德转化的根源。

教师只有以身作则，言行一致，规范自我言行，才能为人师表，引导学生树立正确的道 德观和价值观。荀子曰: “夫师以身为正仪, 而贵自安者也。” ( 《荀子・修身》) 教师要 积极开展自我批评, 每日三省吾身, 正视自己的言行, 有错必改, 无则加勉。“游必择友, 不好苟交。忧德之不来，不患爵之不尊。(《论衡・自纪篇》)

许多古代大儒通过自己的身体力行为我们树立了师德典范。宋代教育家胡瑗以身作则, 事事为学生先。《宋史》中记载: “瑗教人有法, 科条纤悉具备, 以身先之。” 魏晋教育家 颜之推: “人在少年, 神情未定, 所与款狎, 熏渍陶染, 言笑举动, 无心于学, 潜移暗化, 自 
然似之。”只有教师言传身教, 以身作则, 才能达到 “随风潜入夜, 润物细无声” 的教学境 界。

\section{4 因材施教, 教学有方}

孔子是 “因材施教” 理论的先驱，他对其学生的才能、性格了然于胸。孔子在教学中擅 长抓住每个学生的特质, 根据个人资质的不同, 对每个人进行针对性的教学。“中人以上, 可人语上也; 中人以下, 不可以语上也。” (《论语-雍也》) 意指中等资质以上的人, 可 以告诉他深奥的道理; 中等资质以下的人就很难让他了解深奥的道理了。朱喜进一步把因材 施教理论概括为: “夫子教人，各因其材。”（朱喜《论语集注》）墨子也在《耕柱》中谈 到: “能谈辩者谈辩, 能说书者说书, 能从事者从事。”（墨子《耕柱》）又说: “知者必 量其力所能至而从事焉。”（墨子《公孟》）旨在说明要在教育中充分挖掘以及发展学生的 专长, 从学生的接受能力出发, 实施教育。

中国古代的教育者在 “因材施教”的过程中，还要遵守教学规范，“孔子讲学，书必大 管, 语必雅言。” (《说文序》) 注意激发学生的求知欲和积极性, 逐步启发和诱导学生独 立探索和解决问题, “知至学之难易而知其美恶, 然后能博喻, 能博喻然后能为师。” (《礼 记・学记》) 教师要讲究教育方法, 循循善诱, “夫子循循然善诱人, 博我以文, 约我以礼, 欲罢不能。” ( 《论语-子罕》) 温故知新, “子曰: 温故而知新, 可以为师矣。”（《论 语・为政》) 孔子也反复强调要求学生能够常常复习所学的知识, 从中获得新的领悟。

\section{5 学识渊博, 诲人不倦}

古人认为要作为一名合格的师者, 需要不断地学习, 汲取最新的知识, 丰富自我, 实现 知识的创新与传承。“子曰: 若圣与仁, 则吾岂敢? 抑学而不厌, 诲人不倦, 则可谓云尔己 矣。” ( 《论语 - 述而》) 教师首先就应该具有 “学而不厌, 诲人不倦” 的精神品质, 唯有 学而后教, 才能不断在学习中发现不足, 充实自我。孔子终生都在不断的学习, 超越自我, 以致 “发愤忘食, 乐以忘忧, 不知老之将至云尔”。( 《论语・述而》) 孟子有言: “流水 之为物也, 不盈科不行: 君子之志于道也, 不成章不达。”（《孟子・尽心上》）流水唯有 在填满了沟洼后才能继续向前流, 教育者唯有发扬求真、求知的好学精神, 不断用知识武装 自己的头脑才能成源远流长, 满足学生对新的知识的渴求与探知。

“师者, 传道, 授业, 解惑也。”（韩愈《师说》）“子贡问孔子：“夫子圣矣乎？” 曰: “学不厌, 智也; 教不倦, 仁也。仁且智, 夫子既圣矣。”” (《论语・述而》) 孔子 是这样说也是这样做的。孔子视事业重于生命、诲人不倦的教学态度至今仍不失为教师的榜 样。

综上所述，中国几千年的文化传承与积淀，已经形成了较为完善的师德理论体系。

\section{3. 对当代师德建设的启示}

\section{1 爱岗敬业, 无私奉献}

中国古人的教育追求 “为天地立心，为生民立命，为往圣及绝学，为万世开太平”（北 宋张载），强调 “达则兼济天下，穷则独善其身”，普遍具有崇高的人生理想。而在人们心 目中，“师者，传道受业解惑也”，这就决定了教师有强烈的社会责任感和历史使命感。教 师是一个特殊的职业, 正式这个职业赋予他们献身理想的动力。所以, 当代教师也理应具有 安贫乐道、爱岗敬业、辛勤耕耘、无私奉献的高尚品格。

\section{2 严于律己, 为人师表}

我国历代教育家非常重视严于律己, 为人师表的模范作用。孔子就是为人师表的楷模, 他 “躬自厚而薄责于人” (《论语・卫灵公》) 。传统师德主张教师 “严于律己, 宽以待人”, 
“以身作则，为人师表”，一代代的教育家通过身体力行成为各自时代的楷模。身教重于言 教, 古今同理, 教师只有成为 “人之模范” 才会赢得学生的尊敬, 这种育人的理念体现了传 统师德之美。规范自我言行, 力行为人师表, 强调教师在生活工作中, 要做好榜样作用, 规 范自我的言行举止，做到身正为范。

\section{3 业务精湛, 博学知新}

孔子说 “温故而知新, 可以为师矣。” ( 《论语 - 为政》) 是把不断积累知识作为为师 的先决条件, “业务精湛” 无疑是古人对教师提出的基本要求。近人蔡元培先生则从正反两 方而阐明了为师者刻苦钻研、勤奋不辍的必要性, “使教员之知识, 本不丰富, 则不特讲授 之际不能详密, 而学生偶有质问, 不免穷于置对, 启学生轻视教员之心, 而教授之效为之大 减。故为教员者，于其所任之教科，必详博综贯，肆应不穷，而后能胜其任也。”

\section{4 乐教善教, 严慈相济}

传统师德强调实施教师不仅要乐教, 还要善教。古人在教学手段讲究因材施教, 启发诱 导, 循序渐进等方法, 这些都是宝贵的有益经验。教师真正关爱学生就要严格要求学生。老 师要在学业、品行包括日常生活等各个方面严格的要求学生, 在学业上鼓励学生勤勉好学, 熟读精思; 在品行操守方面严于律己, 宽以待人。严与爱是相辅相成的, “师严然后道尊, 道尊然后民知敬学。”（《礼记・学记》）古人认为 “养不教，父之过，教不严，师之惰。” (《三字经》) 教师对学生严且爱, 学生才可能有所成就。

\section{4. 结束语}

加强师德建设是一个综合性系统工程, 需要社会和教师从外部和内部的双向顺利运作, 博采古今师德, 推陈出新, 才能使师德建设再上一个新台阶。对如何传承、发展、用好传统 文化, 2014年2月24日下午, 习近平在主持中共中央政治局就培育和弘扬社会主义核心价值观、 弘扬中华传统美德进行第十三次集体学习时强调： “对历史文化特别是先人传承下来的价值 理念和道德规范, 要坚持古为今用、推陈出新, 有鉴别地加以对待, 有扬弃地予以继承, 努 力用中华民族创造的一切精神财富来以文化人、以文育人。”习近平总书记的讲话对指导当 下我国正在进行的高校师德建设具有极其重要的意义。

\section{致谢}

本文为广东省教育厅 2015 年重点平台及科研项目青年创新人才类项目（社科类）《中国 传统文化视域下的高校师德建设内涵与路径研究》(2015WQNCX173)的阶段性成果之一。

\section{References}

[1] S. K. Goyal, An integrated inventory model for a single supplier-single customer problem, International Journal of Production Research, vol.15, pp. 107-111, 1977.

[2] A. Banerjee, A joint economic-lot-size model for purchaser and vendor, Decision Sciences, vol.17, pp. 292-311, 1986.

[3] S. K. Goyal, A joint economic-lot-size model for purchaser and vendor: A comment, Decision Sciences, vol.19, pp. 236-241, 1988.

[4] R. M. Hill, The single-vendor single-buyer integrated production-inventory model with a generalized policy, European Journal of Operational Research, vol. 97, pp. 493-499, 1997. 